\title{
Hepatitis $C$ virus viremia increases the incidence of chronic kidney disease in HIV-infected patients
}

\author{
Lars Peters $^{a}$, Daniel Grint ${ }^{b}$, Jens D. Lundgren ${ }^{a, c}$, Jürgen K. Rockstroh ${ }^{d}$, \\ Vincent Soriano ${ }^{\mathrm{e}}$, Peter Reiss ${ }^{\mathrm{f}}$, Anna Grzeszczuk ${ }^{\mathrm{g}}$, Helen Sambatakou ${ }^{\mathrm{h}}$, \\ Amanda Mocroft ${ }^{b}$, Ole Kirk ${ }^{a, c}$, for EuroSIDA in EuroCoord
}

\begin{abstract}
Background: Several studies have reported on an association between hepatitis $C$ virus (HCV) antibody status and the development of chronic kidney disease (CKD), but the role of HCV viremia and genotype are not well defined.

Methods: Patients with at least three serum creatinine measurements after 1 January 2004 and known HCV antibody status were included. Baseline was defined as the first eligible estimated glomerular filtration rate (eGFR) (Cockcroft-Gault equation), and CKD was either a confirmed ( $>3$ months apart) eGFR of $60 \mathrm{ml} / \mathrm{min}$ per $1.73 \mathrm{~m}^{2}$ or less for patients with a baseline eGFR more than $60 \mathrm{ml} / \mathrm{min}$ per $1.73 \mathrm{~m}^{2}$ or a confirmed $25 \%$ decline in eGFR for patients with a baseline eGFR of $60 \mathrm{ml} / \mathrm{min}$ per $1.73 \mathrm{~m}^{2}$ or less. Incidence rates of CKD were compared between HCV groups (anti-HCV-negative, antiHCV-positive with or without viremia) using Poisson regression.

Results: Of 8235 patients with known anti-HCV status, 2052 (24.9\%) were anti-HCVpositive of whom $983(47.9 \%)$ were HCV-RNA-positive, 193 (9.4\%) HCV-RNAnegative and $876(42.7 \%)$ had unknown HCV-RNA. At baseline, the median eGFR was 97.6 (interquartile range $83.8-113.0$ ) $\mathrm{ml} / \mathrm{min}$ per $1.73 \mathrm{~m}^{2}$. During 36123 personyears of follow-up (PYFU), 495 patients progressed to CKD (6.0\%) with an incidence rate of 14.5 per 1000 PYFU (95\% confidence interval $12.5-14.9)$. In a multivariate Poisson model, patients who were anti-HCV-positive with HCV viremia had a higher incidence rate of CKD, whereas patients with cleared HCV infection had a similar incidence rate of CKD compared with anti-HCV-negative patients. There was no association between CKD and HCV genotype.

Conclusion: Compared with HIV-monoinfected patients, HIV-positive patients with chronic rather than cleared HCV infection were at increased risk of developing CKD, suggesting a contribution from active HCV infection toward the pathogenesis of CKD.
\end{abstract}

(c) 2012 Wolters Kluwer Health | Lippincott Williams \& Wilkins

AIDS 2012, 26:1917-1926

Keywords: coinfection, hepatitis C virus, HIV, kidney disease, viremia

\section{Introduction}

Although the introduction of combination antiretroviral (ARV) treatment (cART) has resulted in a decrease in
HIV-associated nephropathy, chronic kidney disease (CKD) remains an important cause of morbidity and mortality in HIV-positive patients [1]. Apart from risk factors related to the HIV infection and its treatment,

\footnotetext{
${ }^{a}$ Copenhagen HIV Programme, University of Copenhagen, Copenhagen, Denmark, ${ }^{\mathrm{b}}$ Research Department of Infection and Population Health, Division of Population Health, University College London Medical School, Royal Free Campus, London, UK, ${ }^{\mathrm{c}}$ Department of Infectious Diseases, Rigshospitalet, Copenhagen, Denmark, ${ }^{\mathrm{d} D e p a r t m e n t ~ o f ~ M e d i c i n e ~ I, ~ U n i v e r s i t y ~ o f ~ B o n n, ~ B o n n, ~}$ Germany, ${ }^{\mathrm{E}}$ Infectious Diseases, Hospital Carlos III, Madrid, Spain, ${ }^{\mathrm{f}}$ Academisch Ziekenhuis bij de Universiteit van Amsterdam, Amsterdam, The Netherlands, ${ }^{8}$ Department of Infectious Diseases, Medical University of Bialystok, Bialystok, Poland, and hIppokration General Hospital, University of Athens, Athens, Greece.

Correspondence to Lars Peters, MD, Copenhagen HIV Programme, Faculty of Health Sciences, The Panum Institute, University of Copenhagen, Building 21.1, Blegdamsvej 3B, 2200 Copenhagen, Denmark.
}

Tel: +45 1213545 5764; fax: +45 1213545 5758; e-mail: Ipe@cphiv.dk

Received: 7 March 2012; revised: 4 June 2012; accepted: 22 June 2012. 
HIV-positive patients often have a higher prevalence of traditional risk factors for kidney disease, such as arterial hypertension, diabetes mellitus and smoking, than seen in the background population $[2,3]$.

CKD has been reported to occur more often in HIVpositive patients coinfected with hepatitis $\mathrm{C}$ virus $(\mathrm{HCV})$. $\mathrm{HCV}$ infection has been associated with different nephropathies, especially membranoproliferative glomerulonephritis in patients with mixed cryoglobulinemia $[4,5]$. In the EuroSIDA study, we have previously shown that $\mathrm{HCV}$-seropositive patients had a $75 \%$ increased risk of CKD compared with HCV-seronegative patients [6], and a recent meta-analysis showed that, compared to HIV-monoinfected patients, HIV/HCV-coinfected patients had a nearly $50 \%$ increased risk of CKD [7]. However, in these and other published studies, the HCV diagnosis was based on a positive HCV antibody test only. The influence of HCV viral load and genotype on the risk of development of CKD in patients coinfected with HIV and $\mathrm{HCV}$, therefore, remains to be determined.

In the developed world, chronic HCV infection is predominantly acquired through IDU. A number of renal disorders have been associated with use of illicit drugs (e.g. heroin and cocaine) [8]. In addition, IDU carries a high risk of invasive bacterial infections, which can lead to renal impairment. It is, therefore, likely that some of the increased renal morbidity and mortality seen in HCVpositive patients is due to some of these risk factors and not the HCV per se. Furthermore, in HCV patients with advanced liver disease, HCV could cause CKD indirectly as part of a hepatorenal syndrome [9].

In the EuroSIDA study, we are prospectively following a large cohort of HIV/HCV-coinfected patients, well characterized in terms of HCV-RNA and HCV genotype status. The aim of the present study was, therefore, to investigate the impact of $\mathrm{HCV}$ viremia and genotype on the risk of development of CKD in HIV/ $\mathrm{HCV}$-coinfected patients in the EuroSIDA study.

\section{Patients and methods}

The EuroSIDA study is a prospective, observational cohort of 16594 HIV-1-infected patients followed in 103 centers across Europe, Israel and Argentina. The study has been described in detail previously [6]. In brief, patients were enrolled into eight cohorts from May 1994 onward and last follow-up was in spring 2011. At recruitment, in addition to demographic and clinical information, a complete ART history is obtained, together with the most recent CD4 cell count, plasma HIV-RNA measurements and hepatitis $\mathrm{B}$ and $\mathrm{C}$ status (anti-HCV antibodies, HCV-RNA and genotype). At each followup visit, details on all CD4 cell counts and plasma HIV-
RNA values measured since the last follow-up visit are extracted, as are latest hepatitis B and C status and the dates of starting and stopping each ARV drug received and the use of drugs for prophylaxis against opportunistic infections. The dates of diagnosis of all AIDS-defining illnesses, non-AIDS-defining malignancies and other serious infections are also recorded.

The EuroSIDA plasma repository was set up in 1997 and collects plasma samples from all patients at 6-month intervals and stores them at $-80^{\circ} \mathrm{C}$. Patients with unknown hepatitis B surface antigen ( $\mathrm{HBsAg}$ ) or $\mathrm{HCV}$ serostatus and with stored plasma samples were identified in 2006 and anti-HCV immunoglobulin G and HBsAg in these samples were determined. Serum HCV-RNA was quantified in all anti-HCV-positive samples using the Versant HCV-RNA v3.0 assay (Bayer Diagnostics, Berkeley, California, USA), which has a lower limit of detection of $615 \mathrm{IU} / \mathrm{ml}$.

Patients were included if they fulfilled the following inclusion criteria: a minimum of three serum creatinine measurements measured after 1 January 2004 (date from which serum creatinine has been routinely recorded in the EuroSIDA study), body weight measured within 12 months of each creatinine measurement, recorded date of birth and known HCV antibody status.

\section{Study endpoints}

Development of CKD was defined as either confirmed (at least two measurements at least 3 months apart) estimated glomerular filtration rate (eGFR) of $60 \mathrm{ml} / \mathrm{min}$ per $1.73 \mathrm{~m}^{2}$ or less for patients with an eGFR more than $60 \mathrm{ml} / \mathrm{min}$ per $1.73 \mathrm{~m}^{2}$ at baseline or confirmed $25 \%$ decline in GFR for patients with an eGFR of $60 \mathrm{ml} / \mathrm{min}$ per $1.73 \mathrm{~m}^{2}$ or less at baseline. The eGFR was calculated using the Cockcroft-Gault equation [10]. Sensitivity analyses included using the Modification of Diet in Renal Disease (MDRD) [11] and Chronic Kidney Disease Epidemiology Consortium (CKD-EPI) equations [12] and using an endpoint defined as $25 \%$ decline to less than $60 \mathrm{ml} / \mathrm{min}$ per $1.73 \mathrm{~m}^{2}$ or $25 \%$ decline in patients with baseline eGFR less than $60 \mathrm{ml} / \mathrm{min}$ per $1.73 \mathrm{~m}^{2}$ [International Network for Strategic Initiatives in Global HIV Trials (INSIGHT); C. Wyatt et al, PLoS ONE, in press].

\section{Statistical methods}

Baseline in this analysis is defined as the first creatinine measurement taken after 1 January 2004 from which eGFR is calculated. Descriptive statistics such as $\chi^{2}$-tests or nonparametric Kruskall-Wallis tests were used to compare patient characteristics at baseline. Progression to CKD was investigated using Poisson regression. Individuals were included in the analysis from baseline until the development of a confirmed CKD event, as previously described, or last eGFR measurement. In addition to HCV coinfection, other potential explanatory variables 
included age, sex, race, region of Europe, AIDS at baseline or during follow-up, CD4 T-cell count and nadir, HBsAg status, HIV viral load, previous use of nephrotoxic drugs (including pentamidine, cidofovir, acyclovir, foscarnet and amphotericin), angiotensinconverting enzyme inhibitor use, hypertension, diabetes, baseline eGFR and cumulative exposure to ARV drugs previously found to be associated with increased risk of CKD (tenofovir, indinavir, atazanavir and lopinavir) [13]. Any explanatory variables with $P$ value less than 0.1 in univariate analyses were subsequently included in multivariate analyses. Excluded variables were also tested in the multivariate model to see if their inclusion improved the model fit. Further analyses focusing on the role of HCV viremia and HCV genotype as explanatory variables along with many sensitivity analyses were performed by supplementing or restricting the main model. For categorical analysis HCV viremia was a priori categorized into resolved infection $(<615 \mathrm{IU} / \mathrm{ml})$, low viremia $(615-$ $500000 \mathrm{IU} / \mathrm{ml})$ and high viremia $(>500000 \mathrm{IU} / \mathrm{ml})$.

\section{Results}

\section{Baseline characteristics}

Among 8235 patients included in the analysis, 2052 (24.9\%) were anti-HCV-positive at baseline, of whom 983 (47.9\%) were HCV-RNA-positive, 193 (9.4\%) were HCV-RNA-negative and 876 (42.7\%) had no HCVRNA available at baseline. Patients with no HCV-RNA data available and no plasma available for HCV-RNA measurement were more likely to come from eastern Europe [adjusted odds ratio (aOR) 1.78, 95\% confidence interval (CI) $1.38-2.30, P<0.0001]$ and less likely to come from central Europe (aOR 0.24, 95\% CI 0.16$0.36, P<0.0001)$ than southern Europe and Argentina. They were more likely to have had a previous AIDS diagnosis (aOR 1.36, 95\% CI 1.08-1.72, $P=0.0097$ ), undetectable HIV-RNA (aOR 1.57, 95\% CI 1.26-1.98, $P<0.0001$ ) and have unknown HBsAg status (aOR 3.59, 95\% CI 2.03-6.36, $P<0.0001)$ than HBsAg positive.

Table 1 shows a breakdown of the baseline characteristics according to $\mathrm{HCV}$ serostatus. The anti-HCV-positive and anti-HCV-negative groups differed with respect to most variables. The anti-HCV-positive patients were slightly younger (39 vs. 42 years), more likely to being infected with HIV by IDU (71.5 vs. $2.4 \%$ ), more likely to be current smokers (51.5 vs. $28.3 \%$ ), had lower cART use (81.5 vs. $86.3 \%)$, had lower prevalence of hypertension (14.7 vs. $25.9 \%)$ and had higher eGFR (100.4 vs. $96.6 \mathrm{ml} /$ min per $\left.1.73 \mathrm{~m}^{2}\right)(P<0.0001$ for all comparisons).

Among anti-HCV-positive patients, there were few differences when comparing HCV-RNA-positive with HCV-RNA-negative patients (Table 1). Viremic patients were more likely to be IDU (74.4 vs. $64.3 \%)$, and had lower prevalence of $\mathrm{HBsAg}(5.3$ vs. $14.0 \%)(P<0.0001$ for comparisons). There was no difference in the prevalence of diabetes between the two groups (3.7 vs. $5.2 \%, P=0.32)$. In HCV-RNA-positive patients, the baseline $\log _{10}$-median $\mathrm{HCV}$ viral load was $5.74 \mathrm{IU} / \mathrm{ml}$ [interquartile range (IQR) 5.28-6.22], 468 (46.9\%) had HCV-RNA between 615 and $500.000 \mathrm{IU} / \mathrm{ml}$ and 530 (53.1\%) had viral load more than $500.000 \mathrm{IU} / \mathrm{ml}$.

\section{Factors associated with progression to chronic kidney disease}

A total of 495 patients $(6.0 \%)$ progressed to CKD during 36123 person-years of follow-up (PYFU), resulting in an overall crude incidence of CKD of 13.7 per 1000 PYFU (95\% CI 12.5-14.9). One hundred twenty (24.2\%) events occurred in anti-HCV-positive patients (incidence 14.5 per 1000 PYFU, 95\% CI 11.9-17.1) with 81, seven and 32 events in the HCV-RNA-positive patients (18.7 per 1000 PYFU, 95\% CI 14.7-22.7), HCV-RNAnegative patients (7.8 per 1000 PYFU, 95\% CI 2.1-13.6) and HCV-RNA unknown groups (10.7 per 1000 PYFU, 95\% CI 7.03-14.4), respectively. Three hundred and seventy-five $(75.8 \%)$ events occurred in anti-HCVnegative patients (incidence 13.5 per 1000 PYFU, 95\% CI 12.1-14.8).

The unadjusted and adjusted incidence rate ratios (IRRs) for the development of CKD for all included patients are shown in Fig. 1. In adjusted analysis, age (per 10 years older) and development of AIDS during follow-up were associated with higher incidence rate of CKD, whereas male sex and higher nadir $\mathrm{CD}^{+}$cell count were associated with lower incidence of CKD. Use of tenofovir, atazanavir, indinavir and lopinavir (per year cumulative exposure) were all significantly associated with an increased incidence of CKD. Diabetes was associated with an increased incidence of CKD in univariate analysis (IRR 2.99, 95\% CI 2.32-3.87, $P<0.0001$ ), but was excluded from multivariate analysis due to high colinearity with hypertension. Lower current $\mathrm{CD}^{+}{ }^{+}$cell count and elevated HIV-RNA levels were both associated with an increased incidence of CKD in the univariate analysis, but not after adjustment.

In univariate analyses, HCV serostatus did not influence the incidence of CKD (IRR 1.07, 95\% CI 0.87-1.31, $P=0.54)$. After adjustment, anti-HCV-positive patients had a two-fold increased incidence of CKD compared with anti-HCV-negative patients (IRR 1.85, 95\% CI 1.49-2.30, $P<0.0001)$. The main factors responsible for the change in IRR in the multivariate analysis were the younger age and the higher baseline eGFR of the antiHCV-positive patients compared with the anti-HCVnegative patients. Adjustment for injection drug use as HIV transmission risk group did not change the results, and was not included in the final model due to colinearity between this variable and HCV status. HBsAg serostatus 


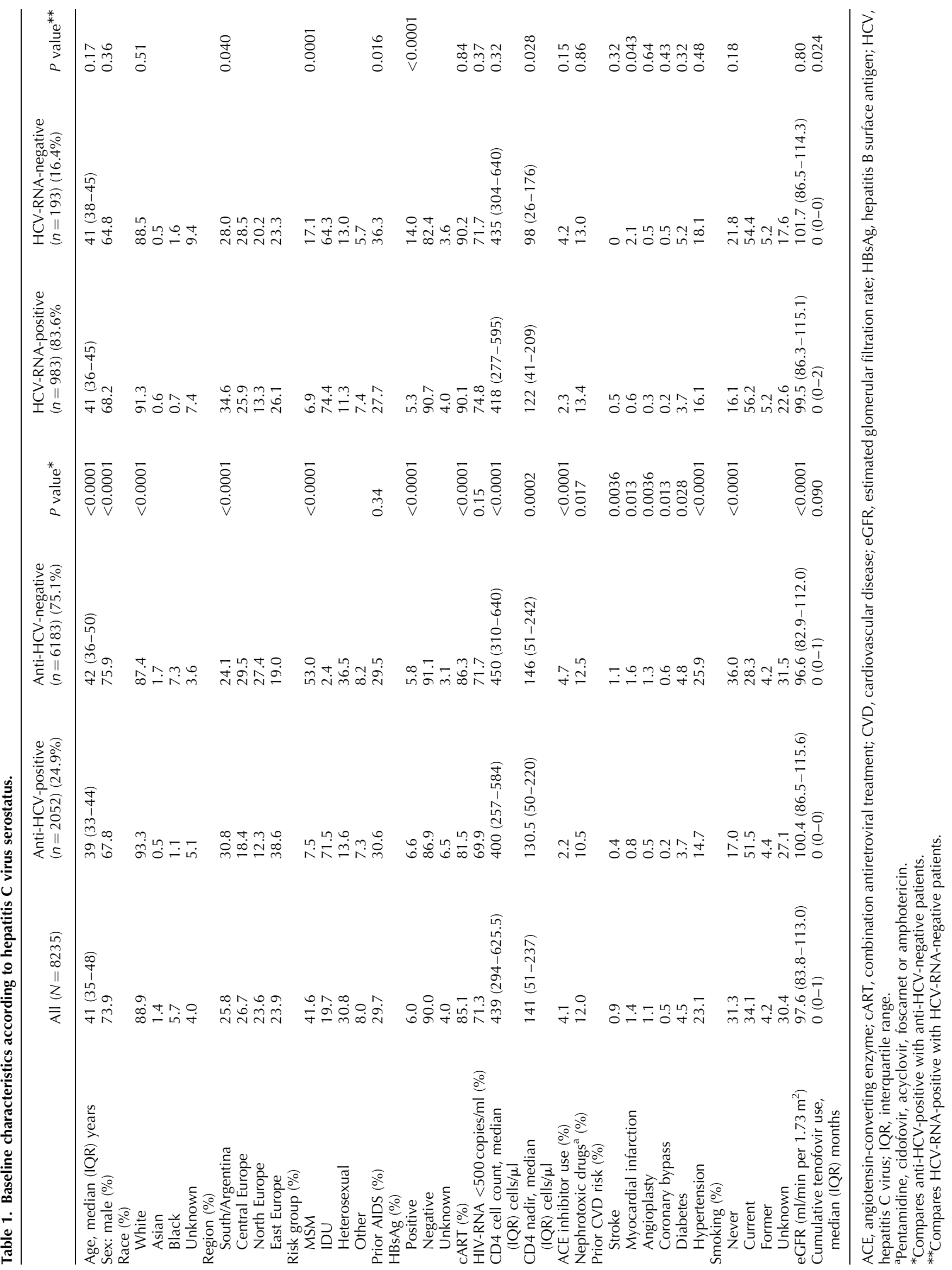




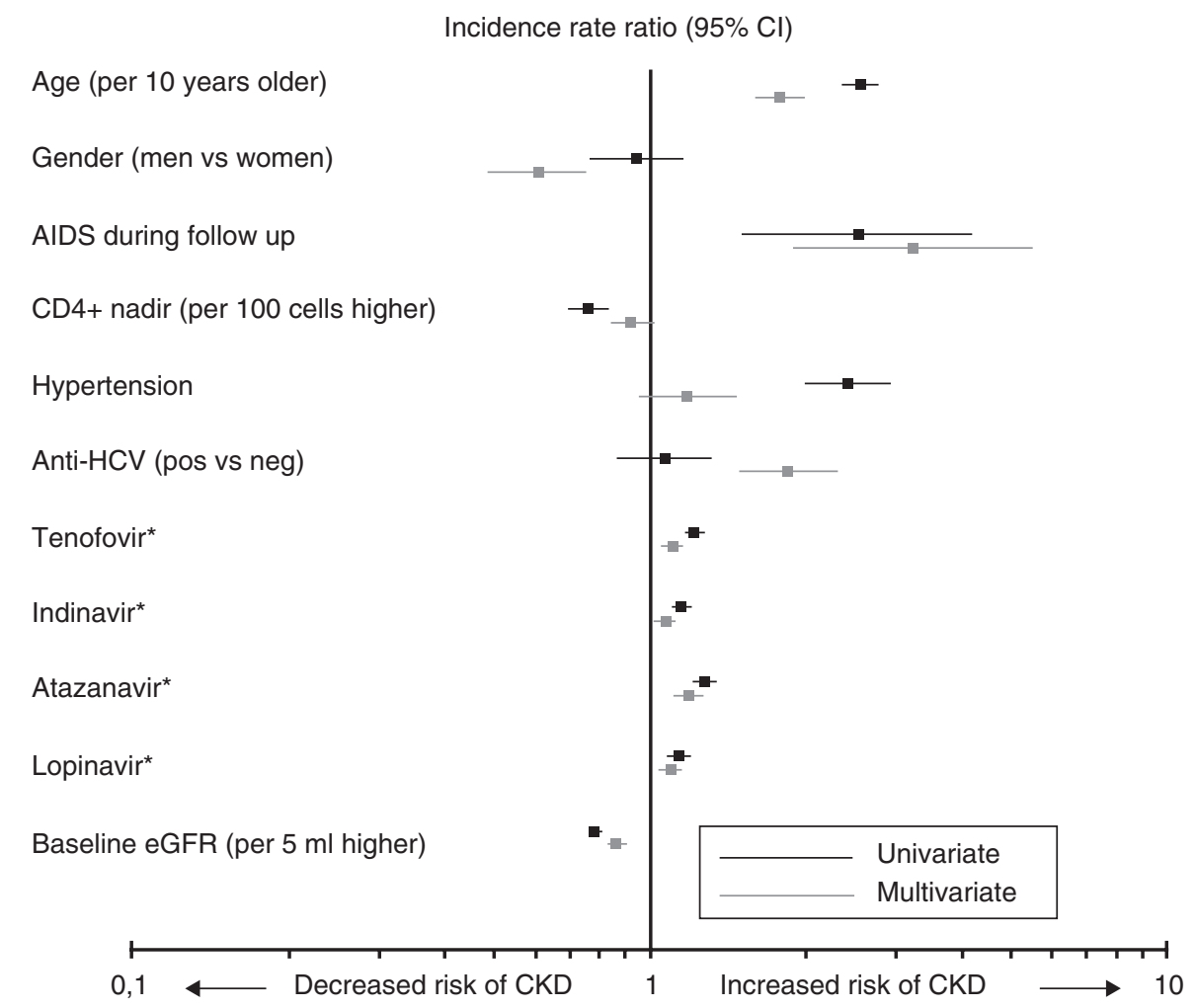

Fig. 1. Incidence rate ratio $(95 \%$ confidence interval) of developing chronic kidney disease in univariate and multivariate analysis. Multivariate analyses adjusted for age*, sex, region of Europe, AIDS at baseline, AIDS during follow-up*, CD4 T-cell count*, CD4 T-cell nadir, HIV-RNA*, use of nephrotoxic drugs*, ACE inhibitor use*, hypertension*, hepatitis C virus (HCV) status*, baseline estimated glomerular filtration rate (eGFR), hepatitis B surface antigen (HBsAg) status* and exposure to tenofovir*, indinavir*, lopinavir* and atazanavir* (per year cumulative exposure). Cl, confidence interval; CKD, chronic kidney disease. *Time-updated variable.

(positive vs. negative) did not influence the incidence of $\mathrm{CKD}$ in either univariate or multivariate analysis.

\section{Hepatitis $C$ virus viremia and genotype and the incidence of chronic kidney disease}

In univariate analysis, there was no difference in the incidence of CKD when comparing anti-HCV-negative patients with anti-HCV-positive patients with resolved infection $(P=0.51)$, unknown viremia $(P=0.15)$ or HCV-RNA between 615 and $500.000 \mathrm{IU} / \mathrm{ml}(P=0.41)$. Patients with HCV-RNA more than $500.000 \mathrm{IU} / \mathrm{ml}$ had a higher incidence of CKD compared with anti-HCVnegative patients, which approached statistical significance (IRR 1.35, 95\% CI 1.00-1.83, $P=0.053$ ) (Fig. 2). After adjustment, those with resolved HCV infection had a similar incidence of CKD as those with anti-HCVnegative patients (IRR 1.17, 95\% CI 0.65-2.09, $P=0.60$ ), whereas patients with HCV-RNA between 615 and $500.000 \mathrm{IU} / \mathrm{ml}$ had an elevated incidence (IRR $1.88,95 \%$ CI $1.31-2.71, P=0.0006$ ), with the highest incidence seen in those with HCV-RNA more than $500000 \mathrm{IU} / \mathrm{ml} \quad(\mathrm{IRR} 2.10,95 \%$ CI 1.54-2.87, $P<0.0001)$. The difference in incidence of CKD for high vs. low viremia was not statistically significant (IRR $1.18,95 \%$ CI $0.75-1.85, P=0.49)$. Fitting HCV-RNA as a continuous variable on the $\log _{10}$ scale, a $1-\log$ increase in HCV-RNA was associated with $9 \%$ increased incidence of CKD, although not statistically significant (IRR 1.09, 95\% CI 0.95-1.24, $P=0.21$ ). For the group with unknown viremia, the incidence of CKD was comparable to the incidence for viremic patients (IRR $1.91,95 \%$ CI 1.26-2.87, $P<0.0021)$. The incidence of CKD did not vary by HCV genotype (IRR 1.06, 95\% CI $0.68-1.65, P=0.81$ for comparing HCV genotype 1 with HCV genotype 2-4).

A sensitivity analysis that included IDUs only, including 1618 individuals and $85 \mathrm{CKD}$ events at an incidence of 13.0 per 1000 PYFU (IQR 10.2-15.7), showed similar results, although the statistical power was reduced. With anti-HCV-positive/HCV-RNA-negative patients as reference, the adjusted IRR for CKD was $1.22(95 \%$ CI $0.49-3.03, P=0.67)$ and 1.99 (95\% CI $0.86-4.61$, $P=0.11)$ for patients with low $(615-500.000 \mathrm{IU} / \mathrm{ml})$ and high HCV viremia $(>500.000 \mathrm{IU} / \mathrm{ml})$, respectively.

The results of the different sensitivity analyses, using other formulae for eGFR, are shown in Fig. 3. Using the MDRD and the CKD-EPI formulae produced similar results as for the Cockcroft-Gault equation. Repeating 


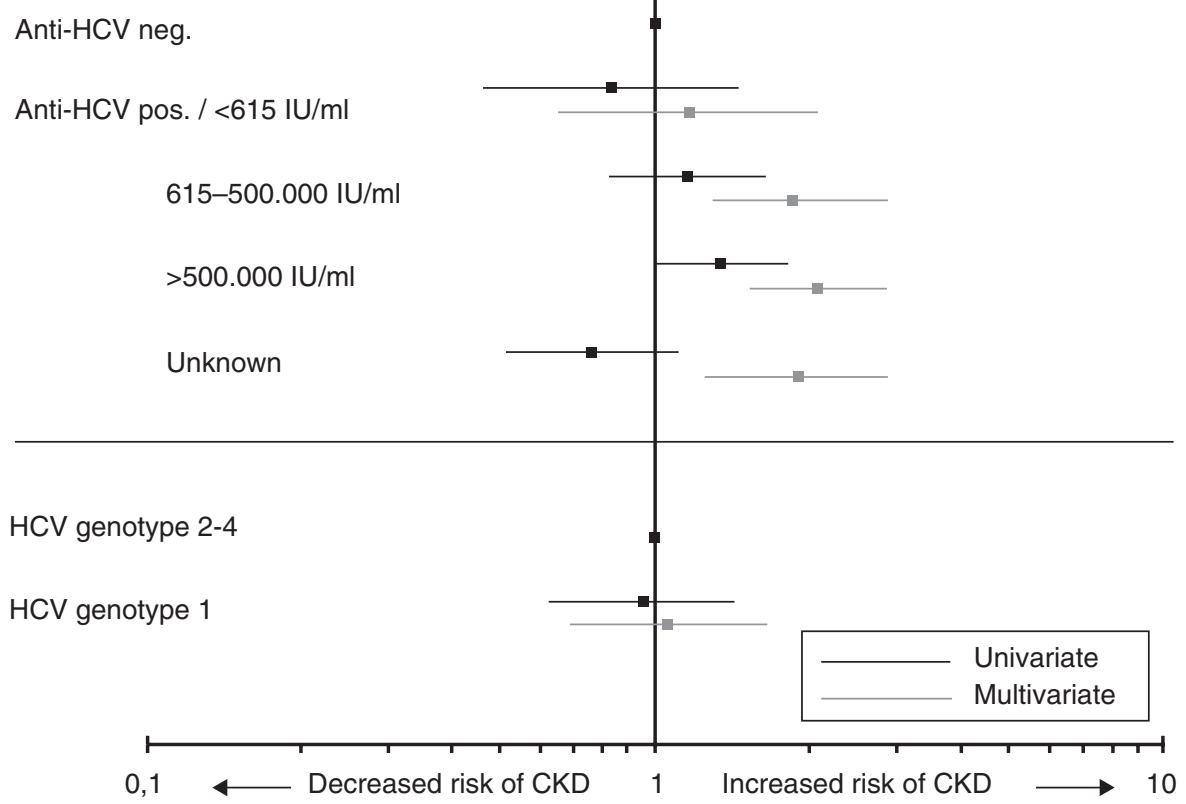

Fig. 2. Incidence rate ratio $(95 \%$ confidence interval) of developing chronic kidney disease according to hepatitis $\mathrm{C}$ virus viral load strata and genotype. Multivariate analyses adjusted for age*, sex, region of Europe, AIDS at baseline, AIDS during followup*, CD4 T-cell count*, CD4 T-cell nadir, HIV-RNA*, use of nephrotoxic drugs*, ACE inhibitor use*, hypertension*, baseline estimated glomerular filtration rate (eGFR), hepatitis B surface antigen (HBsAg) status* and exposure to tenofovir*, indinavir*, lopinavir* and atazanavir* (per year cumulative exposure). $\mathrm{Cl}$, confidence interval; CKD, chronic kidney disease. *Time-updated variable.

the Cockcroft-Gault analysis with a definition of CKD with greater specificity (INSIGHT definition; 25\% decline to $<60 \mathrm{ml} / \mathrm{min}$ per $1.73 \mathrm{~m}^{2}$ or $25 \%$ decline in participants with baseline eGFR $<60 \mathrm{ml} / \mathrm{min}$ per $1.73 \mathrm{~m}^{2}$ ) strengthened the association between $\mathrm{HCV}$ viremia and the incidence of CKD (IRR 2.72, 95\% CI $1.82-4.06, P<0.0001$ ) and (IRR $2.77,95 \%$ CI $1.93-$ $3.98, P<0.0001)$ for low and high viremia, respectively. Comparing high vs. low viremia was not statistically significant $(P=0.94)$

To investigate whether the increased risk of CKD in patients with chronic HCV infection could be due to advanced liver disease, we analyzed the IRR for progression to CKD according to plasma levels of the liver fibrosis marker hyaluronic acid in 682 (69.4\%) antiHCV-positive patients who had this test performed in their first available plasma sample after they were known to be anti-HCV-positive. Fitting hyaluronic acid as a continuous variable on the $\log _{10}$ scale, a $1-\log$ increase in hyaluronic acid was associated with an increased risk of CKD in univariate analysis (IRR 2.64, 95\% CI $1.48-4.69, P=0.0010)$; however, after adjustment for all other variables in Fig. 1, this was no longer statistically significant (IRR 1.74, 95\% CI 0.91-3.34, $P=0.093)$.

\section{Discussion}

The present study is among the first to investigate the association between HCV-RNA viral load, genotype and the incidence of CKD in a large cohort of HIV/HCVcoinfected patients. The incidence of CKD was similar between patients with resolved HCV infection and in anti-HCV-negative patients, whereas patients with chronic HCV infection had a two-fold increased incidence of CKD compared with anti-HCV-negative patients. There was no difference in incidence of CKD when comparing patients with high vs. low HCV viremia. Sensitivity analyses, using the MDRD and the CKD-EPI formulae, gave similar results. To overcome a limitation related to our definition of CKD, which means that patients with a minimal confirmed decrease in eGFR, for example, from 61 to $59 \mathrm{ml} / \mathrm{min}$ per $1.73 \mathrm{~m}^{2}$, would be classified as having CKD; we also used a stricter definition requiring $25 \%$ decline to less than $60 \mathrm{ml} / \mathrm{min}$ 


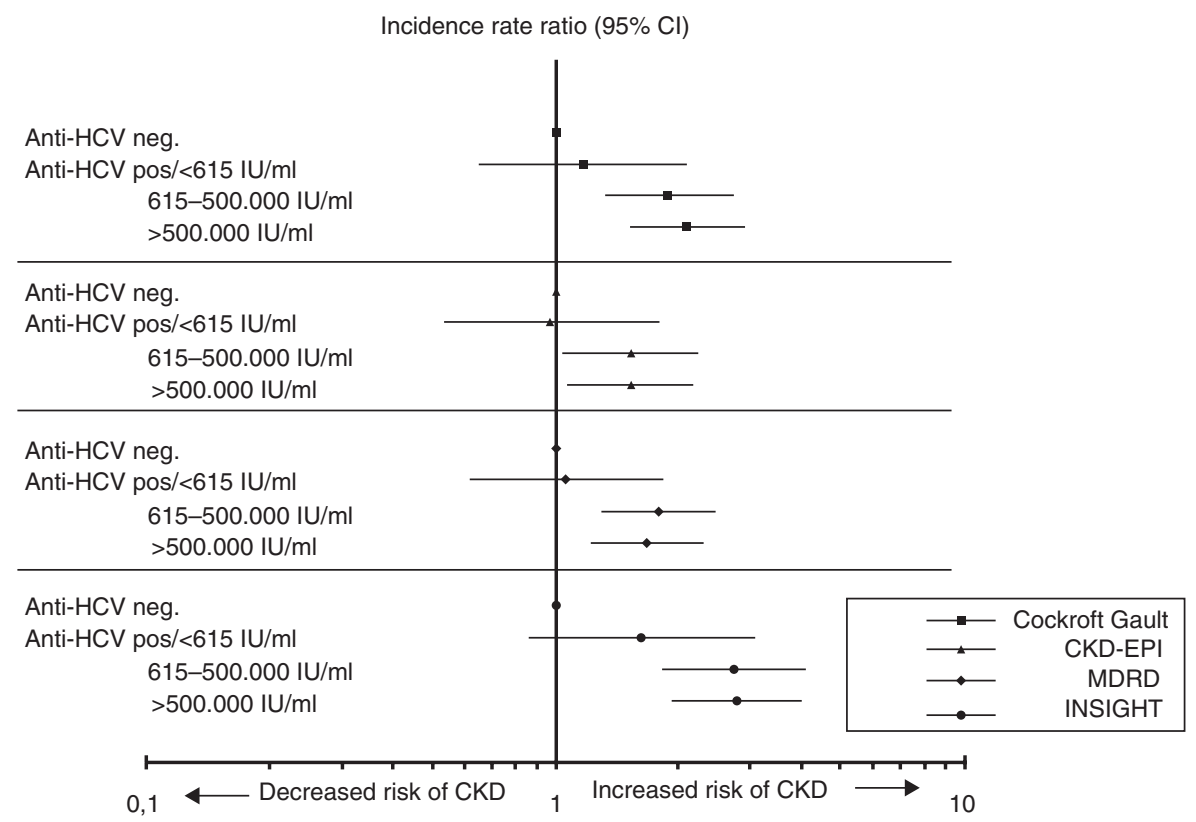

Fig. 3. Sensitivity analyses of incidence rate ratio ( $95 \%$ confidence interval) of developing chronic kidney disease according to hepatitis $\mathbf{C}$ virus viral load strata. Multivariate analyses adjusted for age*, sex, region of Europe, AIDS at baseline, AIDS during follow-up*, CD4 T-cell count*, CD4 T-cell nadir, HIV-RNA*, use of nephrotoxic drugs*, ACE inhibitor use*, hypertension*, baseline estimated glomerular filtration rate (eGFR), hepatitis B surface antigen (HBsAg)* and exposure to tenofovir*, indinavir*, lopinavir* and atazanavir* (per year cumulative exposure). Cl, confidence interval; CKD, chronic kidney disease. *Time-updated variable.

per $1.73 \mathrm{~m}^{2}$ or $25 \%$ decline in participants with baseline eGFR less than $60 \mathrm{ml} / \mathrm{min}$ per $1.73 \mathrm{~m}^{2}$, which only strengthened the association between $\mathrm{HCV}$ viremia and CKD. There were no differences according to HCV genotype. Taken together, these results indicate that the $\mathrm{HCV}$ itself is a significant risk factor for development of CKD in HIV-coinfected patients.

Our results are consistent with findings from a study of $\mathrm{HIV} / \mathrm{HCV}$-coinfected patients enrolled in the standard therapy arms of the Strategic Management of Antiretroviral Therapy and Evaluation of Subcutaneous Proleukin in a Randomized International trials (C. Wyatt et al, PLoS ONE, in press). A recent retrospective study of HCV-monoinfected patients found a 2.5 -fold increased odds of CKD among patients with baseline HCV-RNA more than 700000 copies/ml compared with patients with HCV-RNA less than $700000 \mathrm{IU} / \mathrm{ml}$, but the study was not powered to compare patients with chronic vs. resolved HCV infection [14]. In contrast, a large cohort study by Butt et al. [15] of HIV-negative American male veterans showed no difference in time to development of CKD when comparing individuals with resolved $(n=1793)$ and chronic HCV infection $(n=11822)$. This study differs from ours in several important ways. In the American study, patients were 12 years older and had a much higher prevalence of traditional risk factors for $\mathrm{CKD}$, such as hypertension and diabetes, which could have diminished the relative importance of HCV.

The present study does not allow for conclusions on how $\mathrm{HCV}$ increases the risk of CKD. Many HCV-related nephropathies have been described; the leading cause of $\mathrm{HCV}$-related kidney disease is membranoproliferative glomerulonephritis due to mixed cryoglobulinemia with deposition of HCV containing immune complexes in the glomeruli $[5,16]$. Reported prevalence rates of cryoglobulinemia in $\mathrm{HCV}$ infection vary widely from $36 \%$ to $90 \%$, which can partly be explained by methodological differences, but the prevalence has also been shown to increase with longer duration of $\mathrm{HCV}$ infection and severity of liver fibrosis [4]. However, the prevalence of symptoms related to cryoglobulinemia, such as vasculitis, arthralgia and glomerulonephritis, is much lower than that of cryoglobulinemia. Most studies have found a similar prevalence of cryoglobulinemia in $\mathrm{HCV}$ patients coinfected with HIV [17-19]. In our study, we were not able to characterize the type of CKD, as data on kidney biopsies, cryoglobulinemia and proteinuria were not available.

Further, we cannot rule out that some of the increased risk of CKD in patients with chronic HCV infection could be due to the consequences of IDU. However, our results were similar, although the statistical power 
considerably lower, after exclusion of individuals from HIV transmission risk groups other than IDU. We were not able to evaluate the effect of active IDU in depth at present, as a standardized data collection on these aspects has only recently been implemented.

There was a trend toward increased risk of CKD in patients with elevated levels of the liver fibrosis marker hyaluronic acid, but this did not reach statistical significance after adjustment. However, as only $69 \%$ of all patients had been tested for hyaluronic acid and only at one time point, we cannot rule out that hepatic disease is an important risk factor for CKD in this population; for example, in a retrospective study of $650 \mathrm{HCV}$ patients with cirrhosis, the long-term risk of CKD was 2.7-fold higher among those who did not clear HCV-RNA after interferon treatment [20].

In EuroSIDA, we have previously reported the association between specific ARVs (tenofovir, atazanavir, indinavir and perhaps also lopinavir) and increased risk of CKD, and that the ARV-related nephrotoxicity seems to be reversible [13]. Current guidelines from the European Clinical AIDS Society recommend that HIV patients initiating ART that includes one of these drugs should be monitored more frequently for development of CKD, particularly if they also have other risk factors for CKD [21].

In conclusion, in the EuroSIDA observational HIV cohort, we have shown that chronic, but not resolved $\mathrm{HCV}$ infection, was associated with an increased risk of CKD compared with HIV-monoinfected patients. The exact nature of this association could not be determined in our study. If our results are confirmed by others, future larger studies are warranted to explore the reversibility of $\mathrm{CKD}$ in patients undergoing anti-HCV therapy, and investigate the interaction between $\mathrm{HIV} / \mathrm{HCV}$ coinfection and certain ARV drugs known to be nephrotoxic.

\section{Acknowledgements}

The multicenter study group on EuroSIDA (national coordinators in parenthesis) is as follows:

Argentina: (M. Losso), C. Elias, Hospital JM Ramos Mejia, Buenos Aires. Austria: (N. Vetter), Pulmologisches Zentrum der Stadt Wien, Vienna; R. Zangerle, Medical University Innsbruck, Innsbruck. Belarus: (I. Karpov), A. Vassilenko, Belarus State Medical University, Minsk, V.M. Mitsura, Gomel State Medical University, Gomel; O. Suetnov, Regional AIDS Centre, Svetlogorsk. Belgium: (N. Clumeck), S. De Wit, M. Delforge, Saint-Pierre Hospital, Brussels; R. Colebunders, Institute of Tropical Medicine, Antwerp; L. Vandekerckhove, University Ziekenhuis Gent, Gent. Bosnia-Herzegovina: (V. Hadziosmanovic), Klinicki Centar Univerziteta Sarajevo,
Sarajevo. Bulgaria: (K. Kostov), Infectious Diseases Hospital, Sofia. Croatia: (J. Begovac), University Hospital of Infectious Diseases, Zagreb. Czech Republic: (L. Machala), D. Jilich, Faculty Hospital Bulovka, Prague; D. Sedlacek, Charles University Hospital, Plzen. Denmark: (J. Nielsen), G. Kronborg, T. Benfield, M. Larsen, Hvidovre Hospital, Copenhagen; J. Gerstoft, T. Katzenstein, A.-B. E. Hansen, P. Skinhøj, Rigshospitalet, Copenhagen; C. Pedersen, Odense University Hospital, Odense; L. Ostergaard, Skejby Hospital, Aarhus. Estonia: (K. Zilmer), West-Tallinn Central Hospital, Tallinn; J. Smidt, Nakkusosakond Siseklinik, Kohtla-Jarve. Finland: (M. Ristola), Helsinki University Central Hospital, Helsinki. France: (C. Katlama), Hôpital de la PitiéSalpétière, Paris; J.-P. Viard, Hôpital Necker-Enfants Malades, Paris; P.-M. Girard, Hospital Saint-Antoine, Paris; J.M. Livrozet, Hôpital Edouard Herriot, Lyon; P. Vanhems, University Claude Bernard, Lyon; C. Pradier, Hôpital de l'Archet, Nice; F. Dabis, D. Neau, Unité INSERM, Bordeaux. Germany: (J. Rockstroh), Universitäts Klinik, Bonn; R. Schmidt, Medizinische Hochschule, Hannover; J. van Lunzen, O. Degen, University Medical Center Hamburg-Eppendorf, Infectious Diseases Unit, Hamburg; H.J. Stellbrink, IPM Study Center, Hamburg; S. Staszewski, JW Goethe University Hospital, Frankfurt; J. Bogner, Medizinische Poliklinik, Munich; G. Fätkenheuer, Universität Köln, Cologne. Greece: (J. Kosmidis), P. Gargalianos, G. Xylomenos, J. Perdios, Athens General Hospital, Athens; G. Panos, A. Filandras, E. Karabatsaki, 1st IKA Hospital, Athens; H. Sambatakou, Ippokration Genereal Hospital, Athens. Hungary: (D. Banhegyi), Szent Lásló Hospital, Budapest. Ireland: (F. Mulcahy), St James's Hospital, Dublin. Israel: (I. Yust), D. Turner, M. Burke, Ichilov Hospital, Tel Aviv; S. Pollack, G. Hassoun, Rambam Medical Center, Haifa; S. Maayan, Hadassah University Hospital, Jerusalem. Italy: (S. Vella), Istituto Superiore di Sanità, Rome; R. Esposito, I. Mazeu, C. Mussini, Università Modena, Modena; C. Arici, Ospedale Riuniti, Bergamo; R. Pristera, Ospedale Generale Regionale, Bolzano; F. Mazzotta, A. Gabbuti, Ospedale S Maria Annunziata, Firenze; V. Vullo, M. Lichtner, University di Roma la Sapienza, Rome; A. Chirianni, E. Montesarchio, M. Gargiulo, Presidio Ospedaliero AD Cotugno, Monaldi Hospital, Napoli; G. Antonucci, A. Testa, P. Narciso, C. Vlassi, M. Zaccarelli, Istituto Nazionale Malattie Infettive Lazzaro Spallanzani, Rome; A. Lazzarin, A. Castagna, N. Gianotti, Ospedale San Raffaele, Milan; M. Galli, A. Ridolfo, Osp. L. Sacco, Milan; A. d'Arminio Monforte, Istituto Di Clinica Malattie Infettive e Tropicale, Milan. Latvia: (B. Rozentale), I. Zeltina, Infectology Centre of Latvia, Riga. Lithuania: (S. Chaplinskas), Lithuanian AIDS Centre, Vilnius. Luxembourg: (R. Hemmer), T. Staub, Centre Hospitalier, Luxembourg. The Netherlands: (P. Reiss), Academisch Medisch Centrum bij de Universiteit van Amsterdam, Amsterdam. Norway: (V. Ormaasen), A. Maeland, J. Bruun, Ullevål Hospital, Oslo. Poland: (B. 
Knysz), J. Gasiorowski, Medical University, Wroclaw; A. Horban, E. Bakowska, Centrum Diagnostyki i Terapii AIDS, Warsaw; A. Grzeszczuk, R. Flisiak, Medical University, Bialystok; A. Boron-Kaczmarska, M. Pynka, M. Parczewski, Medical Univesity, Szczecin; M. Beniowski, E. Mularska, Osrodek Diagnostyki i Terapii AIDS, Chorzow; H. Trocha, Medical University, Gdansk; E. Jablonowska, E. Malolepsza, K. Wojcik, Wojewodzki Szpital Specjalistyczny, Lodz. Portugal: (F. Antunes), M. Doroana, L. Caldeira, Hospital Santa Maria, Lisbon; K. Mansinho, Hospital de Egas Moniz, Lisbon; F. Maltez, Hospital Curry Cabral, Lisbon. Romania: (D. Duiculescu), Spitalul de Boli Infectioase si Tropicale; V. Babes, Bucharest. Russia: (A. Rakhmanova), Medical Academy Botkin Hospital, St Petersburg; N. Zakharova, St Petersburg AIDS Centre, St Petersburg; S. Buzunova, Novgorod Centre for AIDS, Novgorod. Serbia: (D. Jevtovic), The Institute for Infectious and Tropical Diseases, Belgrade. Slovakia: (M. Mokráš), D. Staneková, Dérer Hospital, Bratislava. Slovenia: (J. Tomazic), University Clinical Centre Ljubljana, Ljubljana. Spain: (J. González-Lahoz), V. Soriano, P. Labarga, J. Medrano, Hospital Carlos III, Madrid; S. Moreno, J.M. Rodriguez, Hospital Ramon y Cajal, Madrid; B. Clotet, A. Jou, R. Paredes, C. Tural, J. Puig, I. Bravo, Hospital Germans Trias i Pujol, Badalona; J.M. Gatell, J.M. Miró, Hospital Clinic i Provincial, Barcelona; P. Domingo, M. Gutierrez, G. Mateo, M.A. Sambeat, Hospital Sant Pau, Barcelona. Sweden: (A. Karlsson), Venhaelsan-Sodersjukhuset, Stockholm; L. Flamholc, Malmö University Hospital, Malmo. Switzerland: (B. Ledergerber), R. Weber, University Hospital, Zurich; P. Francioli, M. Cavassini, Centre Hospitalier Universitaire Vaudois, Lausanne; B. Hirschel, E. Boffi, Hospital Cantonal Universitaire de Geneve, Geneve; H. Furrer, Inselspital Bern, Bern; M. Battegay, L. Elzi, University Hospital, Basel. Ukraine: (E. Kravchenko), N. Chentsova, Kiev Centre for AIDS, Kiev; V. Frolov, G. Kutsyna, Luhansk State Medical University, Luhansk; S. Servitskiy, Odessa Region AIDS Center, Odessa; M. Krasnov, Kharkov State Medical University, Kharkov. UK: (S. Barton), St Stephen's Clinic, Chelsea and Westminster Hospital, London; A.M. Johnson, D. Mercey, Royal Free and University College London Medical School, London (University College Campus); A. Phillips, M.A. Johnson, A. Mocroft, Royal Free and University College Medical School, London (Royal Free Campus); M. Murphy, Medical College of Saint Bartholomew's Hospital, London; J. Weber, G. Scullard, Imperial College School of Medicine at St Mary's, London; M. Fisher, Royal Sussex County Hospital, Brighton; C. Leen, Western General Hospital, Edinburgh.

Steering Committee: J. Gatell, B. Gazzard, A. Horban, I. Karpov, B. Ledergerber, M. Losso, A. D'Arminio Monforte, C. Pedersen, A. Rakhmanova, M. Ristola, J. Rockstroh (Chair), S. De Wit (Vice-Chair), J. Lundgren, A. Phillips and P. Reiss.
Coordinating Centre Staff: O. Kirk, A. Mocroft, A. Cozzi-Lepri, D. Grint, M. Ellefson, D. Podlekareva, J. Kjær, L. Peters, J. Reekie, J. Kowalska, J. Nielsen, J. Tverland and A.H. Fischer.

EuroSIDA representatives to EuroCoord: O. Kirk, A. Mocroft, J. Grarup, S. de Witt, P. Reiss, A. Cozzi-Lepri, R. Thiebaut, J. Rockstroh, D. Burger, R. Paredes and J. Kjær.

\section{Conflicts of interest}

Primary support for EuroSIDA is provided by the European Commission BIOMED 1 (CT94-1637), BIOMED 2 (CT97-2713), the 5th Framework (QLK2-2000-00773), the 6th Framework (LSHP-CT2006-018632) and the 7th Framework (FP7/2007-2013, EuroCoord 260694) programs. Current support also includes unrestricted grants by Gilead, Pfizer and Merck and Co. The participation of centers from Switzerland was supported by The Swiss National Science Foundation (Grant 108787).

There are no conflicts of interest.

\section{References}

1. Winston J, Deray G, Hawkins T, Szczech L, Wyatt C, Young B. Kidney disease in patients with HIV infection and AIDS. Clin Infect Dis 2008; 47:1449-1457.

2. Gazzaruso C, Bruno R, Garzaniti A, Giordanetti S, Fratino P, Sacchi P, Filice G. Hypertension among HIV patients: prevalence and relationships to insulin resistance and metabolic syndrome. J Hypertens 2003; 21:1377-1382.

3. Brown TT, Cole SR, Li X, Kingsley LA, Palella FJ, Riddler SA, et al. Antiretroviral therapy and the prevalence and incidence of diabetes mellitus in the multicenter AIDS cohort study. Arch Intern Med 2005; 165:1179-1184.

4. Lunel F, Musset L. Mixed cryoglobulinemia and hepatitis $\mathbf{C}$ virus infection. Minerva Med 2001; 92:35-42.

5. Cao Y, Zhang Y, Wang S, Zou W. Detection of the hepatitis $\mathbf{C}$ virus antigen in kidney tissue from infected patients with various glomerulonephritis. Nephrol Dial Transplant 2009; 24:2745-2751.

6. Mocroft A, Kirk O, Gatell J, Reiss P, Gargalianos P, Zilmer K, et al. Chronic renal failure among HIV-1-infected patients. AIDS 2007; 21:1119-1127.

7. Wyatt CM, Malvestutto C, Coca SG, Klotman PE, Parikh CR. The impact of hepatitis $C$ virus coinfection on HIV-related kidney disease: a systematic review and meta-analysis 1. AIDS 2008; 22:1799-1807.

8. Jaffe JA, Kimmel PL. Chronic nephropathies of cocaine and heroin abuse: a critical review. Clin J Am Soc Nephrol 2006; 1:655-667.

9. Gines P, Guevara M, Arroyo V, Rodes J. Hepatorenal syndrome. Lancet 2003; 362:1819-1827.

10. Cockcroft DW, Gault MH. Prediction of creatinine clearance from serum creatinine. Nephron 1976; 16:31-41.

11. Levey AS, Bosch JP, Lewis JB, Greene T, Rogers N, Roth D. A more accurate method to estimate glomerular filtration rate from serum creatinine: a new prediction equation. Modification of Diet in Renal Disease Study Group. Ann Intern Med 1999; 130:461-470.

12. Horio M, Imai E, Yasuda Y, Watanabe T, Matsuo S. Modification of the CKD epidemiology collaboration (CKD-EPI) equation for Japanese: accuracy and use for population estimates. $\mathrm{Am}$ J Kidney Dis 2010; 56:32-38. 
13. Mocroft A, Kirk O, Reiss P, De Wit S, Sedlacek D, Beniowski M, et al. Estimated glomerular filtration rate, chronic kidney disease and antiretroviral drug use in HIV-positive patients. AIDS 2010; 24:1667-1678.

14. Satapathy SK, Lingisetty CS, Williams S. Higher prevalence of chronic kidney disease and shorter renal survival in patients with chronic hepatitis C virus infection. Hepatol Int 2012; 6:369-378.

15. Butt AA, Wang $X$, Fried LF. HCV infection and the incidence of CKD. Am J Kidney Dis 2011; 57:396-402.

16. Pipili C, Ilonidis G, Cholongitas E. Hepatitis C virus and kidney: a strong association with different clinical aspects. Liver Int 2011; 31:1071-1080.

17. Scotto G, Cibelli DC, Saracino A, Prato R, Palumbo E, Fazio V, et al. Cryoglobulinemia in subjects with HCV infection alone, HIV infection and HCV/HIV coinfection. J Infect 2006; 52:294299.
18. Lapinski TW, Parfieniuk A, Rogalska-Plonska M, Czajkowska J, Flisiak R. Prevalence of cryoglobulinaemia in hepatitis $\mathbf{C}$ virusand hepatitis $C$ virus/human immunodeficiency virus-infected individuals: implications for renal function. Liver Int 2009; 29:1158-1161.

19. Ramos-Casals M, Forns X, Brito-Zeron P, Vargas A, Ruiz M, Laguno $M$, et al. Cryoglobulinaemia associated with hepatitis $C$ virus: influence of HCV genotypes, HCV-RNA viraemia and HIV coinfection. / Viral Hepat 2007; 14:736-742.

20. Arase $Y$, Suzuki F, Kawamura Y, Suzuki Y, Kobayashi M, Matsumoto $N$, et al. Development rate of chronic kidney disease in hepatitis $C$ virus patients with advanced fibrosis after interferon therapy. Hepatol Res 2011; 41:946954.

21. European AIDS Clinical Society. http://www.europeanaidscli nicalsociety.org/images/stories/EACS-Pdf/eacsguidelines-v6_ english.pdf. 